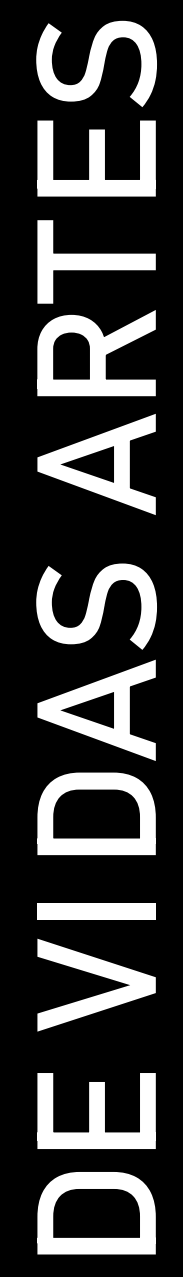

PAULA GUERRA E LÍGIA DABUL (EDS.) 


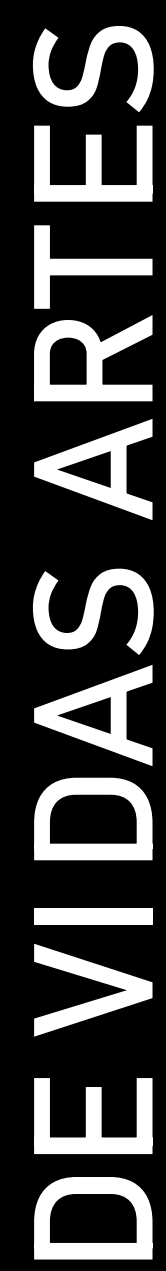

\section{PAULA GUERRA E LÍGIA DABUL (EDS.)}

Design por Irandina Afonso

Ilustração da Capa por Lua Celina

Publicado em Setembro 2019

Universidade do Porto. Faculdade de Letras

[University of Porto. Faculty of Arts and Humanities]

Porto, Portugal

ISBN 978-989-8969-18-7

Suporte: Eletrónico - Formato: PDF / PDF/A 


\title{
IV.1. Glauber Rocha: campo de estudos sobre um cineasta
}

\section{IV.1. Glauber Rocha: field of studies about a filmmaker}

\section{Arthur Arantes Souza}

\section{Resumo}

Este capítulo tem como objeto as teses que estudam o cineasta Glauber Rocha defendidas entre 2006 e 2015 no Brasil. O objetivo da pesquisa é descobrir se há representações sobre o diretor compartilhadas pelos pesquisadores e explicar quais as causas, caso elas sejam encontradas. Para cumprir com o objetivo proposto, foram utilizadas as técnicas de análise de conteúdo para investigar as regularidades nos discursos das teses e a metodologia bibliométrica, a fim de descobrir se as teses partilham uma bibliografia em comum. Foi possivel inferir que há representações constantes nos textos, sobretudo sobre o conteúdo político da obra do cineasta, sua posição como líder e divulgador do cinema nacional e a sua atuação internacional enquanto intelectual que lutava pelo reconhecimento cultural e integração dos países em desenvolvimento. Além disto, 16 especialistas são fontes frequentes para as pesquisas, sendo citados na maioria delas, o que indica um campo de estudo estabelecido.

Palavras-chave: Glauber Rocha, campo artístico, campo científico.

\begin{abstract}
This paper has its object of study in the theses of the filmmaker Glauber Rocha defended between 2006 and 2015 in Brazil. The objective of the study is to find out if there are representations about the filmmaker shared by the researchers in their theses and explain what the causes are, if found. In order to comply with the proposed objective, two techniques were used: the technique of content analysis, used to investigate the regularities in thesis discourses, and the bibliometric methodology, used to find out if the theses share a common bibliography. It was possible to infer that there are constant representations in the texts regarding the political content of the filmmaker's work. Also, there are representations about his stand as a leader and promoter of the national cinema. As an intellectual, his international actuation fought for cultural recognition and integration of developing countries. In addition, 16 specialists are frequent sources for the theses, being cited in most of them, which indicates an established field of study.
\end{abstract}

Key words: Glauber Rocha, artistic field, scientific field.

\section{Introdução}

Glauber Rocha foi um cineasta brasileiro ativo durante os anos 1960 e 1970 e produziu alguns dos principais filmes brasileiros ${ }^{192}$, como O Dragão da Maldade contra o Santo Guerreiro (1969) que Ihe rendeu o prêmio de melhor

\footnotetext{
192 Este capítulo resulta do mestrado do autor intitulado "Glauber Rocha: olhares acadêmicos sobre um cineasta" no Programa de Pós-Graduação em Sociologia da Universidade Federal Fluminense sob orientação científica da Professora Doutora Lígia Dabul.
} 
diretor no Festival de Cannes naquele ano. Contemporaneamente, sua vida e obra continuam interessando cinéfilos e pesquisadores do Brasil, mesmo 37 anos após sua morte. A pesquisa que apresento neste artigo trata justamente dos estudos feitos sobre o diretor em programas de doutorado de todo Brasil entre 2006 e 2015.

Meu objetivo é investigar se os pesquisadores e pesquisadoras compartilham algum tipo de percepção sobre o cineasta e por que eles o fazem. Em outras palavras, busco descobrir se há representações mentais, formas estabelecidas de representar a realidade, fruto da disputa entre agentes de diversos ambientes sociais (Bourdieu, 2008a) e, se existem, por que as pesquisas as reproduzem. Para atingir estes objetivos, aplicarei duas metodologias de pesquisa: a análise de conteúdo e a pesquisa bibliométrica. A primeira me ajudará a destrinchar o texto e, a partir da codificação por temas (Baldin, 1979), descobrir possíveis regularidades nos discursos. A segunda metodologia possibilitará a exploração da bibliografia, permitindo ver se há o compartilhamento de textos de determinados especialistas que indiquem um campo estabelecido de estudos que tenha capacidade de criar tais representações (Melo, 1999).

Na primeira sessão deste artigo, Glauber Rocha: um objeto científico, explicarei detalhadamente os motivos que me conduziram a esta pesquisa, bem como certos procedimentos que serão utilizados. Na parte Metodologia de pesquisa, detalho as técnicas usadas no estudo, as já mencionadas análise de conteúdo e metodologia bibliométrica. No subcapítulo seguinte discutirei os resultados da pesquisa. Como veremos, é possível identificar algumas constâncias nas construções das teses. Três grandes temas norteiam os textos: Cinema e recepção, Atuação social e biografia e Transitos e atuação internacional. Cada um destes assuntos possuem suas representações mentais compartilhadas pelos pesquisadores. A seguir, demonstro como um campo de estudos sobre Glauber Rocha e o cinema estão estabelecidos no Brasil devido à frequência com que determinados especialistas e textos são citados nas teses, além de fazer uma breve discussão sobre a relação entre arte e ciência e como estes dois ambientes influenciam um ao outro. 


\section{Glauber Rocha: um objeto científico}

Glauber Rocha foi um diretor, crítico e teórico de cinema brasileiro. Além disto, foi poeta, escritor, agitador cultural e uma presença marcante nas discussões políticas da segunda metade do século XX. Uma figura controversa e multifacetada, como descreve seu principal biógrafo, João Carlos Teixeira Gomes (1997). Nascido em 1939 em Vitória da Conquista, na Bahia, e falecido em 1981 no Rio de Janeiro, foi marcante por suas obras e personalidade. Seus filmes são considerados realizações essenciais do cinema brasileiro. A Associação Brasileira de Críticos de Cinema (ABRACCINE) elegeu os 100 mais importantes filmes nacionais da história com cinco produções encabeçadas por ele: Deus e o Diabo na Terra do Sol (1963), Terra em Transe (1967), O Dragão da Maldade contra o Santo Guerreiro (1969), Di (1977) e Idade da Terra (1980). Além do reconhecimento nacional, ganhou prêmios internacionais, como o de melhor diretor do festival de Cannes por O Dragão da Maldade (Gomes, 1997).

Apesar de ser difícil mensurar a importância de um indivíduo para a cultura de um país, “já é hora de tirar Glauber do 'gueto' do cinema e inseri-lo na história da cultura e do pensamento contemporâneos, da qual seu cinema faz parte (Bentes, 1997: 9)". Esta afirmação feita por Ivana Bentes (1997), é um dos motivadores desta pesquisa, que busca analisar as investigações feitas no ambiente universitário sobre o diretor. Veremos que há, em diversas áreas do conhecimento, como nas humanidades ou sociologia, pesquisas acadêmicas realizadas sobre ele. Neste artigo pretendo discutir a influência de Glauber Rocha e seus principais interpretes em teses de doutorado defendidas no Brasil entre 2006 e 2015. Escolhi este intervalo de tempo por coincidir com a determinação da Coordenadoria de Aperfeiçoamento de Pessoal de Nível Superior - CAPES - que exige que universidades brasileiras mantenham cópias digitais das teses e dissertações defendidas a partir de 2006. Utilizarei apenas teses no estudo por elas estarem em menor número, o que me permite realizar uma investigação mais profunda. Além disto, programas doutorado, apesar de terem um alto nível de especialização, são espaços de formação acadêmica. Teses são produtos de pesquisas que envolvem uma rede de relações entre estudantes, orientadores e tradições de ensino. Há, desta maneira, diversas rodadas de negociação. De certa forma, a escolha da bibliografia por parte dos futuros doutores passa pelo crivo dos orientadores, o que dá sustentação ao argumento de que estes ambientes 
acadêmicos são esferas importantes de legitimação do conhecimento científico (Melo, 1999). Utilizei como fonte da pesquisa os repositórios online de 82 universidades públicas brasileiras e a base do Instituto Brasileiro de Informação em Ciência e Tecnologia (IBICT), que centraliza a informação de diversas universidades brasileiras. As buscas foram feitas utilizando "Glauber Rocha" como parâmetro, filtrando as ocorrências no título, resumo e palavraschave. Foram encontradas 14 teses e 30 dissertações defendidas no período escolhido, sendo que 12 teses estavam disponíveis on-line.

Ainda que o objeto desta pesquisa sejam as teses de doutorado feitas sobre Glauber Rocha, busco entender a interação entre dois mundos sociais distintos: a arte e a ciência. Segundo o sociólogo francês Pierre Bourdieu (1996, 2007), a sociedade é constituída pelos "campos". Campos são espaços sociais relativos a elementos da sociedade, como a economia, a política, a arte e a ciência. Cada campo possui regras próprias que determinam a quantidade de poder que indivíduos, grupos e entidades possuem no seu interior. Grande parte deste poder é usado para definir as próprias regras do campo que influenciarão na sua hierarquia interna. Diversos agentes sociais disputam a capacidade de determinar as regras do campo para se colocarem em posições mais dominantes. Um aspecto importante da teoria de Bourdieu diz respeito à autonomia relativa a cada campo. Por serem espaços temáticos e com regras próprias, os campos tendem a rejeitar a influência de outros, mas não são capazes de se isolar totalmente. Um bom exemplo disto está na própria relação entre os da arte e da ciência.

Bourdieu (1996) faz um diálogo com a teoria literária e a maneira como ela reage aos estudos de obras feitas pela sociologia. Segundo o autor, existe uma má vontade entre os que defendem a unicidade da literatura e da arte para com as análises científicas. Analisar a arte cientificamente seria uma espécie de reducionismo. Ele se pergunta de onde vem o afã dos escritores em rebaixar o conhecimento racional e de decretar a transcendência da obra de arte. A motivação não é outra senão defender o lugar "distinto" daqueles que produzem a experiência artística e daqueles que compartilham dela no momento da fruição, ou seja, desqualificar que outros em campos distintos tenham capacidades suficientes de estabelecer algum tipo de conhecimento legítimo sobre o que é produzido no interior do campo em questão. 
Isto quer dizer que cientistas se sujeitam a regras do campo jornalístico, como por exemplo, a audiência. Decisões científicas não seriam mais tomadas levando em conta princípios considerados bons pelos próprios cientistas, mas pela repercussão que poderiam gerar, algo típico do jornalismo. Vemos, portanto, que há uma tensão entre pessoas que circulam próximas das fronteiras dos campos. O que não quer dizer que fronteiras não sejam ultrapassadas e que haja a influência de um sobre o outro, como por exemplo, a capacidade do campo jornalístico de influenciar o campo científico descrita por Bourdieu:

Ver reintroduzir-se essa mentalidade-índice-de-audiência até entre os editores de vanguarda, até nas instituições científicas, que se põem a fazer marketing, é muito preocupante porque isso pode colocar em questão as condições mesmas da produção de obras que podem parecer exotéricas (Bourdieu, 1997: 38).

A relação entre o campo artístico e científico, ou seja, entre Glauber Rocha (e seus intérpretes) e as 14 teses de doutorado, que pretendo estudar são os discursos construídos nestes trabalhos acerca do diretor. De forma mais específica, busco investigar se há uma convergência nas formas como os pesquisadores caracterizam o autor e sua obra. Chamarei estas convergências de 'representações mentais', termo cunhado por Bourdieu (2008a), que seriam "atos de percepção e de apreciação, de conhecimento e de reconhecimento" (Bourdieu, 2008a: 107), ou seja, modos de compreender, conhecer e avaliar determinados elementos da vida social criados coletivamente. O estabelecimento de representações mentais está em disputa no interior dos campos e é, de certo modo, uma luta pela capacidade de criar percepções legítimas no mundo (Bourdieu, 2008a). Tenho duas hipóteses acerca desta relação. A primeira é que há uma repetição de representações mentais mobilizadas pelos autores e a segunda é que isso ocorre pela existência de um grupo de autores que dominaram a construção destas representações, sendo o próprio Glauber Rocha um autor central para o estabelecimento da própria imagem. No subcapítulo a seguir, sobre a metodologia de pesquisa explicarei as técnicas utilizadas para testar as hipóteses.

\section{Metodologia de pesquisa}

Como referido, este trabalho tem duas hipóteses que estão entrelaçadas. A primeira afirma que as teses defendidas sobre Glauber Rocha mobilizam representações mentais já estabelecidas. A segunda, que depende da confirmação da primeira, diz que isto acontece porque existe um grupo de 
autores que dominam a construção destas representações. Para testá-las, utilizarei duas técnicas: para a primeira hipótese será feita uma análise de conteúdo e para a segunda aplicarei a metodologia de pesquisa bibliométrica. Utilizarei a análise de conteúdo na introdução dessas teses, pois esta técnica é, segundo Bardin (1979),

Um conjunto de técnicas de análise das comunicações (grifo do autor). Não se trata de um instrumento, mas de um leque de apetrechos; ou, com maior rigor, será um único instrumento, mas marcado por uma grande disparidade de formas e adaptável a um campo de aplicação muito vasto: as comunicações (1979: 31).

A minha incidência nas "Introduções" das teses prende-se com o facto de nelas os autores discutem amplamente as suas pesquisas com elementos como: objetivos, hipóteses, mobilizam algumas referências bibliográficas e resumem os resultados, como bem explicado por Miriam Goldenberg:

Meus relatórios de pesquisa começam com uma introdução onde retomo o
objetivo geral do estudo e os objetivos específicos a ele relacionado. Familiarizo
o leitor com as minhas ideias iniciais, antes de fazer a pesquisa propriamente
dita: o que esperava encontrar, quais as hipóteses de trabalho que me
nortearam, qual o grupo que escolhi e as razões para essa escolha, quais os
conceitos principais e os autores nos quais me apoiei. É um panorama da
pesquisa (grifo meu) (Goldenberg, 2004: 95).

Estes instrumentos oferecidos pela análise de conteúdo podem ser tanto quantitativos quanto qualitativos. Neste trabalho, recorrerei ao instrumento qualitativo para evitar a queda em uma armadilha comum neste tipo de pesquisa: a evidência do saber subjetivo. Por fazer parte da sociedade o sociólogo corre o risco de impor sua subjetividade e suas impressões ao que pesquisa, como os pioneiros do campo Durkheim e Weber chamaram a atenção. Esta metodologia confere legitimidade às construções dos sociólogos, oferecendo maior rigor para as respostas colocadas. Assim, almeja-se a concretização de dois objetivos: ultrapassar as incertezas, que consiste em descobrir se há possiblidade de generalização das descobertas e o enriquecimento da leitura, ou seja, buscar mais profundamente os elementos de discussão do texto (Bardin, 1979).

Existem três passos para a análise do discurso: a pré-análise, a exploração do conteúdo e o tratamento dos resultados. A pré-análise é, basicamente, a preparação para a pesquisa. Nesta fase o pesquisador seleciona os textos a serem explorados e os organiza. A exploração do conteúdo é a etapa de codificação dos objetos. Como busco descobrir se há representações mentais estabelecidas nos estudos sobre Glauber Rocha, o tratamento dos resultados acompanhará a codificação, tendo em vista que, 
através da leitura dos textos, observarei o que os autores das teses mobilizam. De forma geral, a codificação:

Corresponde a uma transformação - efetuada segundo regras precisas - dos dados brutos do texto, transformação esta que, por recorte, agregação e enumeração, permite atingir uma representação do conteúdo, ou da sua expressão, susceptível de esclarecer o analista acerca das características do texto, que podem servir de índices (Bardin, 1979: 103).

Ao codificar não estarei apenas desvelando as regularidades nos argumentos dos autores, mas também a maneira como eles articulam seus argumentos, extraindo as representações mentais que se estabelecem nos textos. Utilizarei a codificação por temas, identificando constâncias argumentativas nas teses.

Para o teste da segunda hipótese aplicarei o método de pesquisa bibliométrica que são análises da frequência com que textos aparecem em estudos de determinada área (Melo, 1999). Apesar de não analisar diretamente como as obras são mobilizadas, é um índice que permite afirmar sua influência no campo. Podemos afirmar que este tipo de análise se baseia no princípio da ciência indiciária (Guinzburg, 2009). A ciência indiciária recorre a fontes indiretas para identificar a ocorrência de determinados fenômenos e é uma prática comum na medicina, onde um conjunto de sintomas geralmente indicam determinadas doenças. Nesta pesquisa não procurarei provas diretas da influência de determinados autores, mas indiretas, ou seja, o número de vezes que aparecem nas referências bibliográficas dos objetos. A seguir, farei uma breve descrição das teses estudadas e a discussão dos resultados da pesquisa a partir dos usos das metodologias que foram apresentadas neste subcapítulo.

\section{Resultados}

Entre 2006 e 2015 foram defendidas 14 teses sobre Glauber Rocha, das quais tive acesso a 12. A seguir enumerarei cada uma delas com uma breve descrição do seu conteúdo:

(1) O cinema tricontinental de Glauber Rocha: política, estética e revolução (1969-1974) de Maurício Cardoso, da História, discute uma série de questões relativas ao pensamento político e estético envolvendo o cinema de Glauber Rocha e o Cinema Novo.

(2) Um "momento crítico de tomada de consciência latino-americana": o cinema moderno da América Latina e as letras de Maria Alzuguir Gutierrez, da Comunicação Social, trata de alguns diretores de cinema 
latino-americanos e sua relação com a literatura, dentre estes, Glauber Rocha.

(3) A sonata de Deus e o Diabolus: nacionalismo, música e o pensamento social no cinema de Glauber Rocha, de André Ricardo Siqueira, das Ciências Sociais, trata da importância da música e dos temas nacionais para a narrativa dos filmes de Glauber Rocha.

(4) A ética revolucionária: utopia e desgraça em Terra em Transe, de Sander Cruz Castelo, da na Sociologia, discute a maneira como Glauber Rocha trata o tema da revolução e dos revolucionários em seus filmes, sobretudo em Terra em Transe, levando em consideração as transformações conjunturais, sobretudo causadas pelo Golpe CivilMilitar de 1964.

(5) Glauber em crítica e autocrítica, de Ana Lígia Leite e Aguiar foi defendida na área de Letras. A autora faz um estudo sobre os posicionamentos políticos e cinematográficos de Glauber Rocha e a maneira como influenciou um projeto de cinema brasileiro.

(6) Glauber Rocha: de Xenofonte a Euclides da Cunha, de Demétrio Panarotto, da Letras, busca demonstrar a influência de $O$ Sertão de Euclides da Cunha e do filósofo grego Xenofonte na obra cinematográfica de Glauber Rocha.

(7) Paulo Emílio e a emergência do Cinema novo: débito, prudência e desajuste no diálogo com Glauber Rocha e David Neves, de Pedro Plaza Pinto, foi defendida na área de Comunicação Social. O tema principal é a forma como Paulo Emílio Sales Gomes influenciou o Cinema Novo a partir de sua atividade intelectual, principalmente na maneira como interagia com Glauber e David Neves.

(8) Aproximações entre cinema e poesia: Glauber Rocha e Manoel de Barros, Alexssandro Ribeiro Moura, da Letras, trabalha as interligações entre as experimentações formais dentro dos filmes de Glauber Rocha e das letras de Manoel de Barros e como eles se interligam politicamente.

(9) As imagens do Brasil na América Latina: permanências na crítica dos cinemas de Glauber Rocha e Walter Salles, de Eliska Altmann, da Sociologia, trada da recepção de obras do cineasta por críticos latinoamericanos.

(10) É que Glauber acha feio o que não é espelho: a invenção do cinema brasileiro moderno e a configuração do debate sobre o ser 
cinema nacional, de Frederico Osaman Amorim Lima, da História, discute a importância de Glauber e seus interlocutores para o estabelecimento de uma visão hegemônica sobre o que é o cinema brasileiro moderno.

O cangaço no cinema brasileiro, defendida na área de Artes e Multimeios por Marcelo Vieira, faz um estudo sobre as diversas maneiras como os temas do cangaço e do cangaceiro apareceram na história do cinema brasileiro, além de fazer algumas considerações sobre Glauber Rocha.

Glauber Rocha, ensaísta do Brasil, tese de Letras defendida na por Arlindo Rebechi Junior faz um estudo sobre a atividade escrita de Glauber Rocha, analisando sua trajetória de crítico e teórico de cinema para entender sua atuação no campo do cinema

A partir da introdução destas teses tentei mapeei as recorrências temáticas sobre Glauber Rocha. O objetivo deste mapeamento é testar a validade da seguinte hipótese: há, no campo de estudo sobre Glauber Rocha, representações mentais sobre o diretor que são compartilhadas pelos autores. Na etapa de codificação das teses, foi possível organizar o conteúdo em três grandes grupos de assuntos: cinema e recepção; atuação social e biografia; e trânsitos e atuação internacional. Dos três grupos, o que possui um número menor de referências e é menos discutido é o trânsitos e atuação internacional do diretor. Cinco dos 12 trabalhos falam sobre sua carreira e relações internacionais. A atuação social de Glauber surge em nove teses e o seu cinema é referenciado em 11 teses. A partir deles buscarei extrair as representações mentais mobilizadas pelos pesquisadores sobre o diretor, as quais descreverei nos subcapítulos a seguir.

\subsection{Cinema e recepção}

O tópico mais debatido pelos autores é o cinema e recepção das obras de Glauber Rocha e a representação mental mais consolidada é a do "Cinema Político". É entre os autores consensual que Glauber Rocha realizou um cinema político, preocupado com o estado da população brasileira, realizando denúncias sobre o descaso e a exploração vivida pelo povo em sua época, além de transmitir uma valorização da identidade nacional e o ideal revolucionário, tanto na narrativa, quanto na estética. As palavras "político/política" e "revolução" estão entre as com cinco letras ou mais que mais se repetem no universo de teses. Politico/política aparece 2200 vezes, 
enquanto revolução é usada 1293 vezes. Excetuando nomes próprios, político/política é a palavra mais usada.

Os trechos a seguir demonstram como os autores mobilizam esta representação sobre o diretor:

O jagunço Antônio das Mortes, alter ego de Glauber, contratado pela lgreja e por latifundiários, dizima aquelas manifestações, no intuito de livrar um casal de camponeses de suas influências deletérias. No final do filme, Manuel e Rosa encontram o mar, metáfora da revolução. Imbuído da visão etapista da revolução brasileira elaborada pelo PCB antes de 1964, o cineasta propugna a ideia de que ela parte da cidade para o campo, uma concepção eminentemente leninista de revolução. O litoral exerce função civilizatória no sertão, mediante a ação do intelectual marxista, que incita a consciência de classe dos sertanejos. Emblemático da radicalização do cineasta, cuja maior inspiração é Eisenstein, é o fato de Manuel, após ser injustiçado, assassinar o patrão, diferentemente do Fabiano de Vidas secas, que prefere migrar (Castelo, 2010: 13).

Como veremos, Glauber toma como esteio sonoro composições populares e eruditas, que também são parte de outro projeto, como o próprio nacionalismo musical, no resgate da tradição popular, urbana e rural utilizadas como matriz para o desenvolvimento das formas eruditas (Siqueira, 2014: 03).

O contexto do último momento da tese se estabelece indagando-se politicamente as posições de Glauber, suas rachaduras, seu conceito de nação, sua interpretação sobre o nacionalismo e o populismo, e este recorte seria, talvez, uma superextensão do espaço em branco ou de certo silêncio deixado pelos trabalhos anteriores, ao falarem do Glauber político sem examinar mais detidamente seu pensamento, apresentando, apenas, o impacto das declarações nas quais o cineasta expunha suas opiniões sobre a arte e a política e a repercussão dessas declarações em seus relacionamentos pessoais e junto ao público. (Aguiar, 2010: 14).

A escolha específica de filmes de Glauber Rocha e Walter Salles como objeto de análise explica-se pelo fato de os dois cineastas expressarem a preocupação em representar aspectos singulares da sociedade brasileira (e latino-americana) em suas obras. Nesse sentido, ambos são lidos como "intelligentsias artísticas" empenhadas em projetos de produção cultural que promovem reflexões sobre identidades nacionais. Tal designação justifica-se diante da importância de ambos no debate cinematográfico nacional e latino-americano e pelo fato de suas obras se enquadrarem na presente proposta de pensar imagens "próprias" ao Brasil (Altmann, 2008: 9).

Os fragmentos acima resumem como os pesquisadores percebem a política no cinema do cineasta baiano. O primeiro fala sobre a maneira como ele constrói seus filmes com uma motivação política transformadora. 0 segundo estende esta percepção para a música e argumenta que a trilha sonora, assim como toda a obra, tenta valorizar a cultura e a identidade nacional. O terceiro trecho aborda o pensamento político do realizador e a sua maneira de interpretar fenômenos da realidade nacional, enquanto no último, trata da preocupação recorrente de Glauber Rocha com o tema da identidade nacional.

\subsection{Atuação social e biografia}

Tratei na categoria atuação social e biografia todas as menções dos autores sobre a vida de Glauber Rocha e sua atividade como escritor de jornais e 
revistas, além das estratégias que ele utilizou para manter-se relevante no cenário nacional e internacional. Duas representações mentais se impõem. A primeira é a de "Liderança Cultural", ou seja, como Glauber Rocha se tornou um porta-voz e um agente privilegiado na disseminação da cultural nacional e latino-americana. A segunda é a percepção de que o diretor viva em conflito com adversários e, eventualmente, aliados. Batizei esta representação de "Indivíduo do Conflito".

Sobre estas representações mentais, gostaria de esclarecer dois pontos: poderia trata-las como elementos objetivos da personalidade do diretor ou uma demonstração do seu caráter ao invés de formas arraigadas de representá-lo. Entretanto, creio que tais escolhas discursivas sejam mediadas por relações sociais, como os conflitos na legitimação de certas representações sobre outras. Bourdieu (2008b) afirma que é comum os biógrafos tratarem da vida do biografado como uma sucessão de eventos que o leva do ponto 'a' ao 'b' como se houvesse gatilhos que determinassem seu modo de vida. Ainda que as pesquisas não adotem a mesma postura, elas dão destaque maior a determinadas atitudes e experiências do que a outras. Um das explicações possíveis para isto está na forma como as representações sobre Glauber Rocha já fazem parte de uma seleção anterior feita no interior do campo. Não há nenhum impedimento aos pesquisadores de tratarem, por exemplo, dos afetos ao invés dos conflitos, contudo, há uma maneira padronizada de enquadrar sua trajetória. Como veremos, a maneira como os pesquisadores abordam a personalidade do diretor e os conflitos em que ele se envolvia estão representados nas seguintes passagens:

\footnotetext{
Privilegiou-se, nesse percurso, o período final da vida de Glauber, momento sempre polêmico e conturbado, tanto pelas alterações promovidas em sua cinematografia (e aqui a película A Idade da Terra representa, paradoxalmente, um ponto final e as reticências), quanto pelo seu envergamento político para 0 lado dos dois últimos generais da ditadura militar brasileira (Aguiar, 2010: 14).

Nada mais distante do que as intempestivas participações de Glauber no cenário internacional, suas posições de ataque frontal à cultura européia, sua condenação sem tréguas ao colonialismo, sua crítica estética ao realismo socialista e as formas dramáticas do cinema político, enfim, suas diatribes e batebocas contra inimigos reais ou imaginários (Cardoso, 2007: 14).

Quando se pensa nos mecanismos de produção de textos para Glauber, a questão se afunila ainda mais, pois é necessário apreender sua luta travada, uma luta simbólica, por sinal, que acontece num território de grande disputa entre as formas de produção, circulação e consagração de obras e textos de intelectuais e artistas (Junior, 2011: 29).
}

Nestes trechos destaco as palavras: "ataque", "disputa" e "polêmica", pois elas resumem a maneira como as teses descrevem a relação entre 
Glauber Rocha e seus adversários e, por vezes, aliados. A palavra ataque é utilizada 75 vezes, polêmica 120 e disputa 64. Mesmo que sejam menos usadas que outras, como revolução, a frequência demonstra como os autores enxergam o cineasta. Liderança Cultural é a representação mental mais recorrente neste tema, aparecendo em oito teses. Os fragmentos que representam melhor esta percepção são:

Os cinemanovistas, Glauber Rocha especialmente, buscando legitimar o movimento, escreveram bastante, produção que encobre artigos publicados em jornais e revistas, manifestos, epistolário, escritos de trabalho e livros de diversos gêneros. Não satisfeitos, produziram autobiografias e outras memórias sobre a corrente cinematográfica, na busca infrene de configurar uma tradição. Estas fontes escritas, ao explicitar a individuação/subjetivação dos cineastas, identificam os "outros" que os auxiliaram a se formar. Logo, foram de grande utilidade (Castelo, 2010: 24).

Da mesma forma que Glauber não foi "eleito" o personagem central deste trabalho. Mas, considero que ele é, enquanto sujeito imerso numa teia de sensibilidades juvenis que se desenvolveu a partir dos anos 1950, alguém que articulou práticas e discursos capazes de dar legitimidade a um começo e desenvolvimento narrativos sobre o Cinema em questão (Lima, 2012: 17).

Na segunda cena, as circunstâncias são outras. Glauber traz a carga de ser reconhecido e consagrado aqui e lá fora. Sua produção cinematográfica lista-se entre as mais importantes para o desenvolvimento do cinema mundial entre 1960 e 1970. É respeitado e goza de autoridade num grande espectro de intelectuais no mundo afora, ainda que estivesse ressentido com muitos deles. Em certa medida, Glauber aqui é promessa cumprida, cuja narrativa registra o fim de sua atuação, em desfecho melancólico de sua longa ação combativa (Juniori, 2011: 17).

O cineasta manteve, ainda, uma rede de amigos entre produtores, críticos e diretores europeus e latino-americanos, cultivando, por correspondência e encontros pessoais, relações afetivas e profissionais que duraram anos e deram origem aos filmes analisados nesta tese. Além disso, os anos vividos no exílio, entre 1971 e 1976, em Cuba, na Itália e na França serviram para aprofundar sua experiência com o cinema mundial (Cardoso, 2007: 17).

As passagens acima resumem bem a forma como a liderança de Glauber Rocha é vista por parte dos pesquisadores. A primeira fala da sua energia enquanto uma jovem liderança do Cinema Novo em busca da consolidação do movimento e de sua linguagem. A segunda lida com um líder maduro, capaz de influenciar a luta pela legitimidade de um modelo de cinema. O terceiro excerto vai mais adiante ao descrevê-lo como uma liderança continental e um intelectual consagrado mundialmente. Na última passagem há um Glauber Rocha articulista, que mobiliza suas redes sociais para evidenciar e dar relevância aos seus filmes e discursos. Todas elas lidam com seu modo de se colocar nos espaços e suas estratégias para tornar-se um ator relevante em várias relações. 


\subsection{Trânsitos e atuação internacional de Glauber Rocha}

O trânsito e atuação internacional de Glauber Rocha é focada em dois vértices: sua relação com o 'terceiro-mundo', e o modo como se relacionava com os países desenvolvidos, sobretudo a Europa. A primeira representação mental utilizada para argumentar sobre a forma como Glauber Rocha tratava os países subdesenvolvidos diz respeito ao seu ideal de articulação estética e política do cinema criado nos continentes pobres, além da sua resistência perante a colonização cultural:

\footnotetext{
Ele estabeleceu as bases deste programa que, embora não chegasse a ser efetivado, conseguiu esboçar o que estaria em jogo. Inspirado numa perspectiva que definiu como "cinema tricontinental", Glauber pretendeu liderar uma revolução cultural que tomaria de assalto o campo cinematográfico mundial (Cardoso, 2007: 15).

Glauber Rocha não somente residiu em Cuba, produzindo junto ao ICAIC (Instituto Cubano del Arte e Indústria Cinematográficos), como também teve fortes laços artístico-ideológicos com as práticas revolucionárias antiimperialistas (Altmann, 2008: 9).
}

O título do artigo é Glauber Rocha par cœur, de tête et dans un corps e a sua fatura se dirige para essa enumeração conclusiva após explicar o desejo do cineasta de um cinema livre, "verdadeiro" e "descolonizado", um cinema empenhado, enfim, na "autêntica expressão de um povo" - através de um cinema "artisticamente e economicamente adulto". Tais vetores articulados, entretanto, na mesma circunvolução de um projeto de cinema cuja energia se investe de uma reflexão de alcance global, sobre a totalidade do problema cultural e sócio político do brasileiro, terceiro-mundista, latino-americano, universal (Pinto, 2008: 85).

Com relação à voz over que se sobrepõe à cena, poderíamos comentar o "portunhol" de Glauber: se este pode ser visto como uma idiossincrasia do cineasta, podemos também interpretá-lo como elemento formal constitutivo do filme, que aponta, uma vez mais, para uma noção de unidade latino-americana, o portunhol figurando aí como língua latino-americana por excelência, que uniria o Brasil à América Hispânica (Gutierrez, 2014: 77).

Em comum, nestes fragmentos, está a percepção de que Glauber Rocha buscava unir as problemáticas do "terceiro-mundo" em um projeto estético e político que produzissem uma integração a partir daquilo que aqueles países teriam em comum: miséria, exploração e colonização. Sua imagem de militante é central para os autores, mesmo que seu projeto se realize apenas parcialmente e de maneira contraditória, já que o único filme realizado fora do país que não tem capital ou locação europeia foi História do Brasil (1972-1974), montado no seu exílio em Cuba. Sobre a relação do cineasta com o hemisfério norte, duas representações se destacam: a de cineasta consagrado, divulgador da cultura brasileira e latino-americana e a de polemista anti-colonização, defensor dos interesses dos países subdesenvolvidos. A primeira representação é descrita da seguinte maneira: 
representação dos intelectuais brasileiros em interlocutores dotados de cultura própria (Cardoso, 2007: 15).

Glauber foi um intelectual de muita mobilidade em suas ações intelectuais e culturais. Esteve ambientado não só no Brasil, como participou de um amplo debate cultural no hemisfério norte. De uma ampla capacidade de adaptação às diversas experiências e circunstâncias que ele enfrentava, seus escritos refletem os passos dessas transformações (Junior, 2011: 30).

Nele, a presença dos atores Francisco Rabal - protagonista de Nazarín (Buñuel, México, 1959), que Glauber elogia no texto "Os 12 mandamentos de Nosso Senhor Buñuel" (2006a) -, e Pierre Clementi - protagonista de Porcile (Pasolini, Itália/França, 1969), ator francês com quem Glauber realizara uma entrevista em Roma junto a Straub, Bertolucci e Jancso - também aponta para o diálogo com a cinematografia europeia (Gutierrez, 2014: 59).

Os trechos mostram um Glauber Rocha com bom trânsito no cenário europeu, em diálogo com outros cineastas, podendo acessar atores de prestígio, além de um respeitado nome com alcance grande o suficiente para ter voz internacionalmente, feito raro dentre intelectuais do hemisfério sul. A segunda relação, contudo, é tratada com traços mais vivos:

\begin{abstract}
Nada mais distante do que as intempestivas participações de Glauber no cenário internacional, suas posições de ataque frontal à cultura européia, sua condenação sem tréguas ao colonialismo, sua crítica estética ao realismo socialista e as formas dramáticas do cinema político, enfim, suas diatribes e batebocas contra inimigos reais ou imaginários (Cardoso, 2007: 12).

Cabezas cortadas (1970) foi realizado por Glauber Rocha na Espanha, logo após Der leone have sept cabezas (Brasil/Itália/França, 1970), rodado na África. Nestes dois filmes, que não foram bem recebidos pela crítica europeia, Glauber entabula um diálogo com o pensamento cinematográfico que circulava então, principalmente na Europa (Gutierrez, 2014: 58).

Bastou que a notícia da exclusão da premiação de seu A idade da terra circulasse para que começassem seus protestos cheios de discursos inflamados, algo entre a indignação e a raiva. Ali mesmo no saguão do Hotel Excelsior, Glauber encontrou Louis Malle, um dos premiados, e sem medir palavras deixa clara sua posição ao cineasta francês: "você ganhou o Leão de Ouro porque as cartas estavam marcadas, você venceu porque o seu filme foi produzido pela Gaumont, uma multinacional imperialista". Na sua cabeça, "Malle é um cineasta de segunda classe", e tal como os outros dois premiados Cassavetes e Angelopoulos -, não faziam jus ao prêmio (Junior, 2011: 22).
\end{abstract}

É possível notar por estas passagens que os pesquisadores observam uma ambiguidade na relação entre o diretor baiano, críticos e artistas dos países desenvolvidos. Por um lado a colaboração e a admiração, por outro a repulsa à maneira como os países desenvolvidos tratavam seus contrapartes pobres. O último fragmento demonstra como, próximo do fim de sua vida, esta ambiguidade se tornou conflito total, com o distanciamento entre o diretor e 0 establishment cinematográfico europeu e americano.

Levando em consideração o que expus nestes três últimos subcapítulos, vemos que as teses orbitam em torno de poucas representações mentais comuns dentro dos três assuntos principais, 
validando, assim, a hipótese proposta. Em resumo, os pesquisadores representam o cineasta como um artista e intelectual engajado, defensor apaixonado da integração política e cultural dos países subdesenvolvidos e um militante anti-colonialismo cultural respeitado em todo mundo, mesmo envolvolvido constantemente em conflitos com aliados e adversários para defender o que acreditava, além de ser uma liderança de um cinema nacional que tinha como objetivo unir a renovação estética com causas políticas revolucionárias. Se existem representações firmadas sobre o diretor, elas se originam a partir de disputas de legitimidade dentro de determinado campo. Apesar de não conseguir analisar o momento do conflito ou o processo de estabelecimento destas representações, no próximo subcapítulo demonstrarei que existe um grupo restrito de autores que são referências para os estudos sobre o cineastas.

\subsection{O campo de estudos sobre Glauber Rocha}

Após corroborar a primeira hipótese e apontar as representações mentais que existem sobre Glauber Rocha, neste subcapítulo pretendo ratificar minha segunda hipótese, a de que o compartilhamento de representações por parte dos autores das teses vem do uso de uma bibliografia recorrente. Como expus na discussão metodológica, farei o uso da metodologia bibliométrica (Melo, 1999) para atestar a frequência com que determinadas obras e autores são utilizados. Aponto que para serem elegíveis para o estudo, o autor deve ter pelo menos duas obras citados em mais de uma tese. Adotei este critério por considerar que é um indicativo de que estes especialistas possuem uma reflexão mais detida sobre cinema ou sobre Glauber Rocha. Com isto em conta, foram encontrados 16 intelectuais.

Deles, Jean-Claude Bernadet e Ismail Xavier são os que possuem mais trabalhos citados nas teses, com sete livros cada, seguidos por Glauber Rocha e por Paulo Emílio Sales Gomes, com seis e cinco obras, respectivamente. Além disto, os quatro autores possuem a maior presença nos trabalhos. Ismail Xavier e Glauber Rocha são referências em todas as teses, enquanto Gomes e Bernadet são referenciados em dez pesquisas. Outros autores são relevantes, como vemos no quadro abaixo, mas deixo o destaque para os quatro. 
Tabela IV.1.1: Número de obras citadas por autores com mais de uma obra citada e número de teses em que Glauber está presente

\begin{tabular}{|l|c|c|}
\hline \multicolumn{1}{|c|}{ Autores } & N.o de obras citadas & $\begin{array}{c}\text { N.o Teses em que Glauber está } \\
\text { presente }\end{array}$ \\
\hline BERNARDET, Jean-Claude & 7 & 10 \\
\hline XAVIER, Ismail & 7 & 12 \\
\hline ROCHA, Glauber & 6 & 12 \\
\hline GOMES, Paulo Emilio Sales & 5 & 10 \\
\hline AVELLAR, José Carlos & 4 & 7 \\
\hline AUMONT, Jacques & 3 & 7 \\
\hline BOURDIEU, Pierre & 2 & 5 \\
\hline CAETANO, Maria do Rosário & 2 & 4 \\
\hline DELEUZE, Gilles & 2 & 5 \\
\hline EISENSTEIN, Sergei & 2 & 5 \\
\hline GERBER, Rachel & 2 & 8 \\
\hline NAGIB, Lúcia & 2 & 6 \\
\hline NEVES, David E & 2 & 3 \\
\hline SALEM, Helena & 2 & 3 \\
\hline STAM, Robert & 2 & 7 \\
\hline VIANY, Alex & 2 & \\
\hline
\end{tabular}

A frequência com que estes autores aparecem nas bibliografias e 0 volume de obras que eles possuem nestes trabalhos demonstra a importância que eles têm para o campo de estudo sobre Glauber Rocha e o cinema no Brasil. Esta é uma evidência de que há pouca margem para que os pesquisadores que escreveram teses sobre o assunto façam grandes modificações ou escapem das representações mentais perenes, pois se encontram dentro de relações de dominação, onde autores consagrados, mesmo que não diretamente, conseguem se impor sobre os outros e suas formulações se tornam canônicas para aquele campo em questão.

Podemos afirmar que eles se tornam relevantes dentro de um campo de estudo a partir de uma série de relações dentro dos seus campos respectivos, seja ele da arte ou da ciência (Bourdieu, 2004). Glauber Rocha é o símbolo destas relações e grande parte das pistas se encontram nas próprias teses. Sua potência e influência, descrita por diversos pesquisadores, ultrapassam as fronteiras do cinema e se colocam sobre os intelectuais que pesquisam sobre ele. Seus livros, como veremos na próxima tabela, podem se tornar guias para os trabalhos. Mesmo que inadvertidamente, os pesquisadores podem reproduzir noções que estão préestabelecidas dentro dos escritos do cineasta (e de outros indivíduos) e quando não as reproduzem, é contra elas que os estudos se colocam. Esta relação entre pesquisador e pesquisado demonstra como interagem dois 
campos distintos. A ciência interfere no campo da arte quando discute questões relativas ao último, como a obra e vida de um cineasta, e o campo da arte revida pela potência do próprio objeto escolhido: ele foi um grande produtor de conhecimento sobre si próprio, levando as regras da arte para dentro do jogo científico.

Tabela IV.1.2: Livros presentes em seis ou mais teses

\begin{tabular}{|l|c|}
\hline \multicolumn{1}{|c|}{ Livro } & $\begin{array}{c}\text { N.o de } \\
\text { Teses }\end{array}$ \\
\hline ROCHA, Glauber. Revolução do Cinema Novo & 12 \\
\hline ROCHA, Glauber. Revisão crítica do cinema brasileiro & 11 \\
\hline $\begin{array}{l}\text { XAVIER, Ismail. Alegorias do subdesenvolvimento - Cinema Novo, } \\
\text { Tropicalismo, Cinema Marginal }\end{array}$ & 10 \\
\hline BERNARDET, Jean-Claude. Brasil em tempo de cinema. & 9 \\
\hline XAVIER, Ismail. Sertão mar: Glauber Rocha e a estética da fome & 9 \\
\hline ROCHA, Glauber. O século do cinema & 9 \\
\hline GOMES, Paulo Emilio Sales. Cinema: trajetória no subdesenvolvimento & 9 \\
\hline XAVIER, Ismail. O cinema brasileiro moderno & 8 \\
\hline VIANY, Alex. O processo do Cinema Novo & 8 \\
\hline ROCHA, Glauber. Cartas ao Mundo & 8 \\
\hline $\begin{array}{l}\text { GERBER, Raquel. O mito da civilizaça atlântica: Glauber Rocha, cinema, } \\
\text { política e a estética do inconsciente }\end{array}$ & 8 \\
\hline BERNADET, Jean-Claude. Historiografia clássica do cinema brasileiro & 6 \\
\hline XAVIER, Ismail. O olhar e a cena & 6 \\
\hline VIANY, Alex: Introdução ao cinema brasileiro & 6 \\
\hline GERBER, Rachel; GOMES, Paulo Emílio Sales (orgs). Glauber Rocha & 6 \\
\hline BERNARDET, Jean-Claude. Cinema Brasileiro: propostas para uma história & 6 \\
\hline GOMES, João Carlos Teixeira. Glauber Rocha, esse vulcão & 6 \\
\hline
\end{tabular}

Outro aspecto que gostaria de chamar atenção é sobre as áreas do conhecimento dos especialistas mais referenciados pelos estudos. A maior parte deles são teóricos do cinema, não sendo, necessariamente "pesquisadores", em um stritu sensu, como o próprio Glauber Rocha. Dos 16 autores, 12 são teóricos ou críticos de cinema, acadêmicos ou não. Vale indicar que a maioria das teses não foram defendidas em estudos cinematográficos de crítica ou teoria, mas em áreas como Letras e Ciências Sociais. Partindo das evidências apresentadas, é possível afirmar que a segunda hipótese que apresentei está correta. O número restrito de especialistas sobre cinema e Glauber Rocha recorrentes nas teses é uma das formas de explicar porque seus autores trabalham sobre um número pequeno de representações mentais, reproduzindo certas percepções existentes acerca do cineasta. Concomitantemente, foi possível visualizar certa influência do campo artístico sobre o científico e vice-versa, uma vez que os estudos são interdisciplinares nos dois caminhos: o campo científico tenta desvelar aspectos da criação e trajetória de um artista e utilizam, para isto, 
referências que não são, especificamente, do campo científico, mas da teoria do cinema e da crítica, além da importância do próprio Glauber Rocha para os estudos sobre si.

\section{Considerações finais}

Como pudemos ver neste capítulo, Glauber Rocha é objeto de diversas teses de doutorado defendidas entre 2006 e 2015 nas mais variadas áreas, como Letras, História e Ciências Sociais. Com temas variados, estas pesquisas possuem uma coisa em comum: trabalham sobre representações mentais que pouco variam de uma a outra. Com o uso da análise de conteúdo, identifiquei três temas principais nos estudos: cinema e recepção, atuação social e biografia e trânsitos e atuação internacional. Cada um destes temas possui suas representações mentais. Em Cinema e recepção, a representação mais utilizada é a do cinema político. Segundo os autores, a obra do diretor é marcada pelo forte subtexto político objetivando a denúncia das condições vividas pela população brasileira e a mudança social radical (Cfr. Lima e Guerra, 2016). Em Trânsitos e atuação internacional dá-se atenção às relações que o cineasta têm com o hemisfério norte e sul, seja o conflito com o primeiro ou os ideais com relação ao segundo. Em Atuação social e biografia, as pesquisas falam sobre sua condição de líder cultural e dos embates que se envolveu com adversários e aliados.

A seguir, verifiquei que existe um campo de estudos estabelecido sobre Glauber Rocha e que o diminuto número de especialistas aos quais os pesquisadores recorrem é uma das formas de explicar a constância nas representações mentais existentes nas teses. Autores como Glauber Rocha, Paulo Emílio Sales Gomes, Jean-Claude Bernardett e Ismail Xavier despontam como os mais importantes, por terem tanto um grande número de obras citadas, como estão presentes na maioria das teses estudadas. Por fim, argumentei que a relação entre campo científico e artístico, pelo menos para o universo desta pesquisa, é forte. A influência mútua pode ser notada principalmente pela influência que Glauber Rocha tem sobre as investigações, como pela interdisciplinaridade das mesmas e dos autores aos quais elas recorrem.

\section{Referências Bibliográficas}

Aguiar, A. L. L. e (2010). Glauber em crítica e autocrítica (Tese de doutoramento). Universidade Federal da Bahia, Salvador. 
Altmann, E. (2008). As imagens do Brasil na América Latina: permanências na crítica dos cinemas de Glauber Rocha e Walter Salles (Tese de doutoramento). Universidade Federal do Rio de Janeiro, Rio de Janeiro.

Bardin, L. (1979). Análise de conteúdo. Lisboa: Edições 70.

Bentes, I. (1997). Cartas ao mundo. São Paulo: Companhia das Letras.

Bourdieu, P. (2004). Os usos sociais da ciência: por uma sociologia clínica do campo científico. São Paulo: Editora Unesp.

Bourdieu, P. (2007). Economia das trocas simbólicas. São Paulo: Perspectiva.

Bourdieu, P. (1996). As regras da arte: gênese e estrutura do campo literário. São Paulo: Companhia das Letras.

Bourdieu, P. (2008a). Economia das trocas linquísticas. São Paulo: EDUSP.

Bourdieu, P. (2008b). Razões práticas. Campinas: Papirus Editora.

Cardoso, M. (2007). O cinema tricontinental de Glauber Rocha: política, estética e revolução (1969-1974) (Tese de doutoramento). São Paulo: Universidade de São Paulo, São Paulo.

Castelo, S. C. (2010). A ética revolucionária: utopia e desgraça em Terra em Transe (1967) (Tese de doutoramento). Fortaleza: Universidade Federal do Ceará.

Ginzburg, C. (2009). Mitos, emblemas, sinais. Morfologia e história. São Paulo: Companhia das Letras.

Goldenberg, M. (2004). A arte de pesquisar. Rio de Janeiro: Editora Record.

Gomes, J. C. T. (1997). Glauber Rocha: esse vulcão. São Paulo: Nova Fronteira.

Gutierrez, M. A. (2014). Um momento crítico de tomada de consciência latinoamericana: o cinema moderno da américa latina e as letras (Tese de doutoramento). São Paulo: Universidade Federal de São Paulo.

Junior, A. R. (2011). Glauber rocha, ensaísta do Brasil (Tese de doutoramento). São Paulo: Universidade de São Paulo.

Lima, F. O. A. (2012). É que Glauber acha feio o que não é espelho: a invenção do cinema brasileiro moderno e a configuração do debate sobre o ser cinema nacional (Tese de doutoramento). Uberlândia: Universidade Federal de Uberlândia.

Lima, F. O. A. \& Guerra, P. (2016). Filme, espelho e caleidoscópio: infância, nulificação, docilidade e medo em Aniki-Bóbó, de Manoel de Oliveira. Tempo (Niterói, online), Vol. 22, n. ${ }^{\circ} 40$, pp. 283-301.

Melo, M. P. da C. e (1999). Quem explica o Brasil. Juiz de Fora: Editora UFJF.

Moura, A. R. (2013). Aproximações entre cinema e poesia: Glauber Rocha e Manoel de Barros (Tese de doutoramento). Goiania: Universidade Federal de Goiás. 
Panarotto, D. (2012). Glauber Rocha: de xenofonte a Euclides da Cunha, de Euclides da Cunha a Xenofonte (Tese de doutoramento). Florianópolis: Universidade Federal de Santa Catarina.

Pinto, P. P. (2008). Paulo Emílio e a emergência do Cinema Novo. Débito, prudência e desajuste no diálogo com Glauber Rocha e David Neves (Tese de doutoramento). São Paulo: Universidade de São Paulo.

Siqueira, A. R. (2014). A sonata de Deus e o diabolus: nacionalismo, música e o pensamento social no cinema de Glauber Rocha (Tese de doutoramento). São Paulo: Universidade Estadual Paulista.

Vieira, M. D. S. (2007). O cangaço no cinema brasileiro (Tese de doutoramento). Campinas: Universidade Estadual de Campinas.

\section{Outras Referências}

Rocha, G. (1963). Deus e o Diabo na Terra do Sol [Motion Picture]. Brasil: Copacabana Filmes/Luiz Augusto Mendes Produções Cinematográficas.

Rocha, G. (1967). Terra em Transe [Motion Picture]. Brasil: Copacabana Filmes/Luiz Augusto Mendes Produções Cinematográficas. Brasil: Mapa Filmes.

Rocha, G. (1969). O Dragão da Maldade contra o Santo Guerreiro [Motion Picture]. Brasil: Mapa Filmes/Claude Antoine Films.

Rocha, G. (1977). Di [Motion Picture]. Brasil: Embrafilme.

Rocha, G. (1989). Idade da Terra [Motion Picture]. Brasil: C.P.C. Cinematografica/Centro de Produção e Comunicação (C.P.C.)/Embrafilme/Filmes 3/Glauber Rocha Comunicações Artísticas. 